\title{
Human Recombinant Granulocyte-Macrophage Colony-stimulating Factor and Interleukin 3 Cause Basophil Histamine Release
}

\author{
Mary Haak-Frendscho, ${ }^{*}$ Naoko Arai, ${ }^{\ddagger}$ Ken-ichi Arai, ${ }^{*}$ Maria L. Baeza, ${ }^{*}$ Albert Finn, ${ }^{*}$ and Allen P. Kaplan* \\ *Division of Allergy, Rheumatology, and Clinical Immunology, State University of New York, Stony Brook, Health Sciences Center, \\ Stony Brook, New York 11798-8161; and ${ }^{\ddagger}$ DNAX Research Institute of Molecular and Cellular Biology, Palo Alto, California
}

\begin{abstract}
Histamine-releasing factors (HRFs) have been shown to be released from a variety of human cells, including $T$ lymphocytes and alveolar macrophages. We considered the possibility that known cytokines might possess such activity on human basophils and/or mast cells and therefore tested preparations of human recombinant IL 3, IL 4, IL 5, granulocytè colonystimulating factor (G-CSF) and granulocyte-macrophage colony-stimulating factor (GM-CSF) upon a panel of basophil donors. IL 3 and GM-CSF possessed significant histamine-releasing activity in 8 of 10 and 12 of 14 subjects, respectively. In each instance, a dose response could be demonstrated. IL 4 and G-CSF had no such activity, whereas IL 5 had activity in only 2 of 14 donors tested. We conclude that IL 3 and GM-CSF represent two effective HRFs, and suggest that HRF, as isolated based upon histamine-releasing activity, is likely to be heterogeneous in terms of molecular identity. Whether previously described HRFs relate specifically to IL 3 or GM-CSF must await primary sequence analysis of $\mathrm{HRF}$ and/or studies with monospecific antisera.
\end{abstract}

\section{Introduction}

Histamine-releasing factors (HRFs) ${ }^{1}$ active upon basophils and/or mast cells have been identified as products of alveolar macrophages $(1,2), T$ lymphocytes $(3,4)$, platelets $(5)$, neutrophils (6), mononuclear cell mixtures (7-9), and nasal washings (10). None is as yet purified, although partial characterizations have been published. It is not known whether these represent multiple factors possessing a common activity or a single major gene product that is produced by multiple cell types. Although it is critical that such factors be directly purified, it is also important to test known cytokines that might possess such activity. IL 1 has been reported to cause histamine release from

Address reprint requests to Dr. Allen P. Kaplan, Division of Allergy, Rheumatology, and Clinical Immunology, Health Sciences Center, State University of New York at Stony Brook, Stony Brook, NY 11798-8161.

Received for publication 25 June 1987 and in revised form 28 December 1987.

1. Abbreviations used in this paper: G-CSF, granulocyte colony-stimulating factor; GM-CSF, granulocyte-macrophage colony-stimulating factor; HBS-HSA, Hepes-buffered saline containing 3\% HSA; hr, human recombinant; HRF, histamine-releasing factor; HRF-MNC, human mononuclear cell-derived histamine releasing factor.

J. Clin. Invest.

(c) The American Society for Clinical Investigation, Inc.

0021-9738/88/07/0017/04 \$2.00

Volume 82, July $1988,17-20$ basophils in $\sim 30 \%$ of subjects (11-13), yet it has been distinguished from the mononuclear cell-derived HRF (8). The histamine-releasing activity of tumor necrosis factor is equivocal (13). IL 2, $\gamma$-IFN, and B cell growth factor do not cause histamine release. In this manuscript, we have tested human recombinant (hr) IL 3, 4, and 5 as well as hr granulocyte colonystimulating factor ( $\mathrm{hr}$ G-CSF) and hr granulocyte-macrophage colony-stimulating factor ( $\mathrm{hr}$ GM-CSF). We report herein that IL 3 and GM-CSF are potent HRFs, reactive with most subject basophils. IL 5 had moderate activity, but only in two of 14 donors. IL 4 and G-CSF are negative in all subjects.

\section{Methods}

Preparation of lymphokines. Lymphokine cDNA clones pCD-hGMCSF (14), pCD-hIL 3 (Otsuka, T., unpublished data), pCD-hIL 4 (15), pCD-hIL 5 (16), and pCD-hG-CSF (Arai, K., unpublished data) were transfected into Cos 7 cells (17) by DEAE dextran procedure. These culture supernatants were harvested 4 or $8 \mathrm{~d}$ after transfection and were used in most of the experiments to be presented. One unit (see below) corresponds to $0.25 \%$ Cos transfection supernatant. We also purchased small quantities of purified IL 3 and GM-CSF from Genzyme Corp. (Boston, MA). Their concentrations are 50 and $100 \mathrm{ng} / \mathrm{ml}$, respectively, corresponding to $10^{8} \mathrm{CFU} / \mathrm{mg}$ for IL 3 , and $5 \times 10^{7}$ $\mathrm{CFU} / \mathrm{mg}$ for GM-CSF. One CFU is defined as the amount of growth factor that produces a single colony (50 cells) from $7.5 \times 10^{4}$ human bone marrow cells in soft agar in $14 \mathrm{~d}$.

Selection of donors. Basophils from healthy laboratory volunteers were used. The donors were not prescreened for their capacity to release histamine in response to cytokines, but rather were a random sampling made up of atopic and nonatopic individuals. Atopic subjects had a history of seasonal rhinitis, asthma, or atopic dermatitis and had positive skin tests to a battery of antigens. Nonatopic subjects had no history (or family history) of allergy and were skin-test negative to all antigens tested.

Basophil isolation and histamine release. $1 \mathrm{ml} / 0.2 \mathrm{M}$ EDTA was added to $10 \mathrm{ml}$ blood and $2 \mathrm{ml} \mathrm{3 \%}$ dextran-3\% glucose PBS solution. The cells were allowed to sediment for $40 \mathrm{~min}$ at $37^{\circ} \mathrm{C}$ in $50-\mathrm{ml}$ polypropylene conical tubes (Falcon Labware, Becton, Dickinson, \& Co., Oxnard, CA). The supernatant was aspirated and the cells washed twice with Hepes-buffered saline containing 0.3\% HSA (HBS-HSA) followed by centrifugation at $300 \mathrm{~g}$ for $10 \mathrm{~min}$. The cell pellets were resuspended in HBS-HSA made up in $50 \% \mathrm{D}_{2} \mathrm{O}, 2 \mathrm{mM} \mathrm{CaCl}_{2}$, and 2 $\mathrm{mM} \mathrm{MgCl} 2$ at $30 \times 10^{6}$ cells $/ \mathrm{ml}$. Basophils varied from 0.5 to $2.0 \%$ in such preparations, as assessed using a Giemsa stain. Cell viability was $\geq 98 \%$ by trypan blue exclusion. 3,000,000 cells were added to $1.5-\mathrm{ml}$ microfuge tubes containing $170 \mu$ l HBS-HSA in $50 \% \mathrm{D}_{2} \mathrm{O}$ with $\mathrm{Ca}^{++}$ and $\mathrm{Mg}^{++}$and $30 \mu \mathrm{l}$ of test sample. The microfuge tubes were incubated for $40 \mathrm{~min}$ in a $37^{\circ} \mathrm{C}$ waterbath. Cells were boiled for $10 \mathrm{~min}$ to determine total histamine content in the basophils. The background spontaneous release was determined by adding $30 \mu \mathrm{l}$ of HBS-HSA in place of the test sample. Tubes were centrifuged at $650 \mathrm{~g}$ for $5 \mathrm{~min}$ and the cell-free supernatants were collected. Samples that were not immediately assayed for histamine content were stored at $-20^{\circ} \mathrm{C}$ and assayed within a week. 
Histamine assay. The radioenzyme assay for histamine was performed using a modification of the method of Beaven et al. (18) and has been previously described in detail (8). Standard curves for each assay were constructed by linear regression. The assay results were determined from the standard curve using a computer program, written by Dr. Michael Silverberg (State University of New York, Stony Brook, NY), and run on an Apple Ile computer.

Statistical analysis. Analysis of differences in mean histamine release in response to the cytokines was performed by using the $t$ test.

\section{Results}

The ability of hr IL 3 and hr GM-CSF to release histamine from human basophils is shown in Fig. 1. The hr IL 3 was tested in 10 subjects, 8 of whom responded and 2 of whom had no histamine release $(<5 \%)$ at any concentration tested. Of those eight, a dose response from $10 \%$ of the assay volume to $0.01 \%$ was obtained for each individual tested. Fig. $1 \mathrm{~A}$ shows

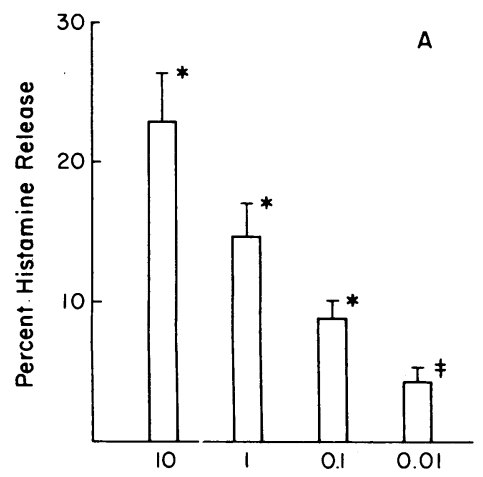

Percent Assay Volume - hr IL-3

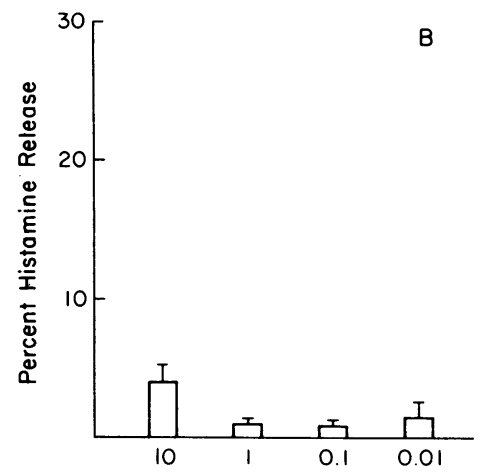

Percent Assay Volume $-\mathrm{hr} \mathrm{IL}-4$

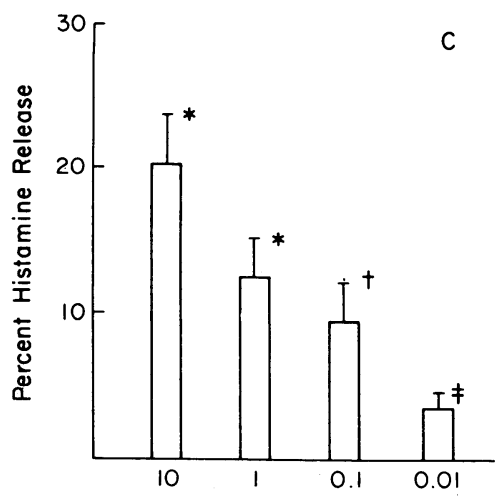

Percent Assay Volume - hr GM-CSF the mean and standard error for histamine release at each dose tested in all eight responders. A clear dose response is obtained and can be contrasted with Fig. $1 B$, in which responsiveness of all 12 donors was negative to hr IL 4. hr GM-CSF was tested in 12 donors, 10 of whom responded significantly (Fig. $1 C$ ). The mock Cos-conditioned media control gave $1 \pm 1 \%$ histamine release in all experiments. IL 5 was tested in a total of 14 donors, 2 of whom were positive (data not shown) and 12 of whom were negative. hr G-CSF (in contrast to GM-CSF) was negative in all 14 donors.

We next attempted to quantitate the Cos supernatant material by comparison with the purified IL 3 (Genzyme) and GM-CSF. Since 1 unit was defined as $0.25 \%$, Cos supernatant the range of Fig. 1 would correspond to 0.04 to 40 units. Because the unit defined by the two sources is similar, this would correspond to $0.4-400 \mathrm{pg} / \mathrm{ml}$ for IL 3 and $8-800 \mathrm{pg} / \mathrm{ml}$ for GM-CSF. A dose response encompassing this range (10fold dilutions) was then performed with the purified material that was tested on basophils of two known responders. The results were similar to that depicted in Fig. 1 (data not shown), in that significant release between 10 and $50 \%$ was observed for all but the most dilute sample tested. $\mathrm{D}_{2} \mathrm{O}$ was routinely used in this and all subsequent experiments to augment secretion and conserve reagents. However, we performed a dose response with IL 3 and GM-CSF in the absence of $\mathrm{D}_{2} \mathrm{O}$. The background release is decreased from $2-4 \%$ to nondetectable, the peak values with either cytokine are diminished fivefold and with anti-IgE are diminished by $2-2.5$-fold.

We next compared responsiveness of atopic and nonatopic subjects with both hr GM-CSF and hr IL 3, each of which was tested at $10 \%$ assay volume and corresponded to the highest value shown in Table I. It is clear that the atopic status of the

Table I. Assessment of hr GM-CSF and IL 3 in Atopic vs. Nonatopic Subjects*

\begin{tabular}{lcc}
\hline & $\begin{array}{c}\text { hr Gm-CSF } \\
(10 \% \text { vol/vol })\end{array}$ & $\begin{array}{c}\text { hr IL 3 } \\
(10 \% \text { vol/vol })\end{array}$ \\
\hline \multicolumn{2}{c}{ \% histamine release } \\
Nonatopic subjects & \multicolumn{2}{c}{} \\
1 & \multicolumn{2}{c}{} \\
2 & 2 & 2 \\
3 & 10 & 4 \\
4 & 7 & 15 \\
5 & 7 & 15 \\
6 & 41 & 21 \\
7 & 48 & 35 \\
8 & 13 & 12 \\
Atopic subjects & 21 & 46 \\
1 & & \\
2 & 21 & 24 \\
3 & 9 & 8 \\
4 & 45 & 20 \\
5 & 5 & 6 \\
& 40 & 39 \\
\hline
\end{tabular}

* A single experiment indicating the mean percent histamine release of duplicate samples using basophils derived from atopic or nonatopic subjects. Atopic subjects have allergic rhinitis and/or asthma and are clearly skin-test positive. Nonatopic subjects have no personal or family history of allergy and all were skin-test negative, except subject 7 , who had two positive tests. 
individual does not predict responsiveness to either GM-CSF or IL 3, although some subjects in each group were nonresponsive. Higher concentrations were not tested.

Fig. 2 shows the response of a single donor's basophils to each of the aforementioned cytokines and to HRFs obtained from human mononuclear cells (HRF-MNC) and platelets. The ordinate is given as percent of total assay volume and corresponds to $10,1,0.1$, and $0.01 \%$, respectively, as in Fig. 1 . An anti-IgE positive control is shown at the top. A dose response is seen with both sources of HRF, hr IL 3, and hr GM-CSF, whereas hr G-CSF, hr IL 4, hr IL 5, and control media (mock Cos) are negative.

The kinetics of cytokine-induced histamine release were examined as shown in Fig. 3. In sharp contrast to the rapid release caused by anti-IgE, the cytokines have a lag time followed by a slow rate of histamine release.

In separate experiments, we sought synergism by combining any of the lymphokines with HRF or by combining active or inactive lymphokines with each other. The results were always additive and not synergistic.

\section{Discussion}

HRFs derived from activated lymphoid cells were first described by Thueson et al. (7), who demonstrated that incubation of concentrated conditioned media with basophils induced histamine release. This was later shown to be a product of T lymphocytes $(3,4)$. Subsequently, other groups have reported HRF from alveolar macrophages $(1,2)$, neutrophils (6), platelets (5), and nasal washings (10), although the relationship among these various sources of HRF is unknown. We have previously reported partial purification of one such HRF; its molecular weight was 30,000 and it had two major charge species at $\mathrm{pH} 6.9$ and $7.3(8)$. We also demonstrated nonidentity of this factor(s) with IL 2, $\gamma$ IFN, B cell growth factor, and IL 1 . On the other hand, IL 1 has been shown to be capable of causing histamine release in $\sim 30 \%$ of donors $(12,13)$. It thus appears likely that histamine-releasing activity is a property of multiple cytokines.

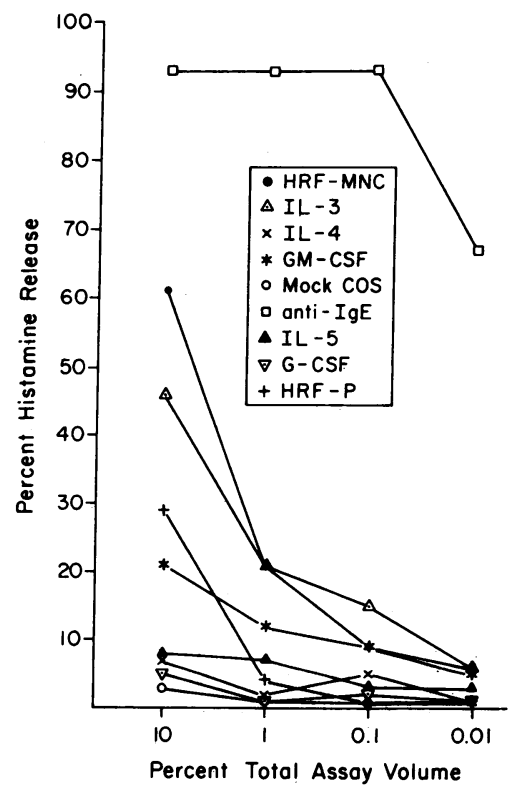

Figure 2. Histamine release determined using a single donor in response to the entire panel of substances tested. Anti-IgE served as a positive control. Dose response curves were induced by $\mathrm{hr}$ IL 3, hr GM-CSF, HRFMNC, and platelet-derived HRF, whereas hr G-CSF, hr IL 4, hr IL 5, and the control supernatant (mock Cos) were all negative.

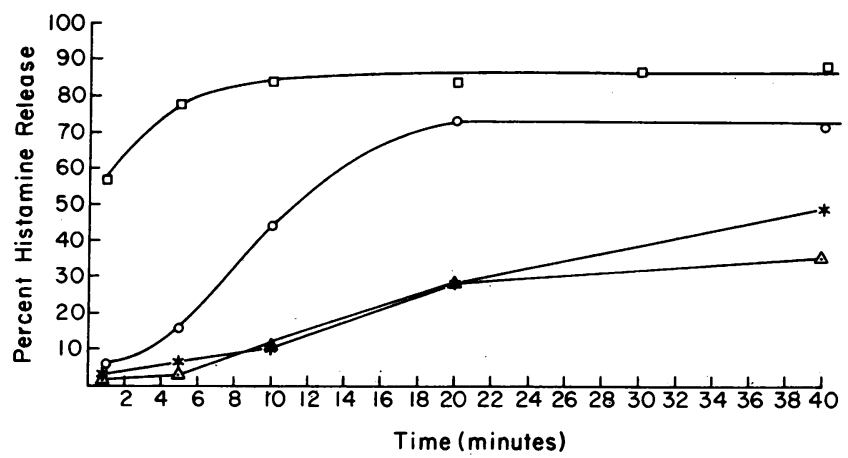

Figure 3. Kinetics of histamine release. Anti-IgE-induced histamine release was rapid and complete within $5 \mathrm{~min}$. HRF-MNC-induced release was half-maximal between 5 and $10 \mathrm{~min}$. Half-maximal release caused by hr IL 3 and hr GM-CSF was attained at 10-20 min. 口, anti-IgE; O, HRF-MNC; *, hr GM-CSF; $\Delta$, hr IL 3.

In this manuscript, we have extended our studies of cytokines to include ILs 3, 4, and 5, G-CSF, and GM-CSF. Our results indicate that IL 3 and GM-CSF can each cause histamine release and most subjects' basophils were responsive to each. There was also no obvious effect of atopic vs. nonatopic subject status in terms of responsiveness to IL 3 or GM-CSF, as has been reported for some preparations of HRF (2). Although atopics are, in general, more responsive, our use of $\mathrm{D}_{2} \mathrm{O}$ clearly facilitates histamine release to cytokines. The basophil source used in these studies is a mixture of leukocytes in which the percentage of basophils is similar to that seen in a normal differential. We thus have not ruled out the possibility that these cytokines (or other sources of HRF) cause histamine release indirectly by acting on some other cell type.

Like HRF, the rate of histamine release caused by either of these agents is much slower than that observed with anti-IgE (Fig. 3, reference 2). Although our preparations of HRF appear to act somewhat faster than IL 3 or GM-CSF, we do not feel this can be taken as evidence of nonrelatedness, since the HRF used is a mixture and we have not studied the relationship of dose to the rate of histamine releașe.

IL 3 and GM-CSF are clearly multipotent cytokines with effects on many cell types $(19,20)$. Both of them act at early stages of white blood cell differentiation. IL 3, in particular, has been shown to be important for the maturation of a subset of mast cells in rodents known as mucosal mast cells (21). Although somewhat controversial, most recent evidence suggests a similar heterogeneity in humans $(22,23)$. Because histamine is a secretory product of such cells, it is of considerable interest that IL 3 causes histamine release. Although the studies herein were confined to basophils, human HRF has also been shown to cause secretion from mast cells (24). The capacity of IL 3 to cause histamine release may represent one mechanism by which $T$ cell function and manifestation of immediate hypersensitivity may be linked. IL 4 (B cell-stimulating factor-1) also links cellular immunity and immediate-type hypersensitivity since it stimulates IgE synthesis (25) and causes proliferation of connective tissue-type mast cells (26). But IL 4 clearly does not stimulate basophil histamine release. Diseases such as chronic urticaria are characterized by a perivascular infiltration of $\mathrm{T}$ lymphocytes and monocytes with increased numbers of dermal mast cells $(27,28)$ and local histamine release $(29,30)$. It is possible that both IL 3 and 4 are responsi- 
ble for some of these manifestations. GM-CSF is a multipotential CSF active on virtually all cell lineages, including erythroid precursors and megakaryocytes. It is not known to stimulate mast cells, but probably acts on granulocyte precursors that will ultimately differentiate into basophils.

The relationship of IL 3 or GM-CSF to the HRFs that have been described is unknown. We hope to use monospecific antisera to these cytokines in cross-blocking experiments and immunoblotting studies of HRF. We also will obtain sufficient primary sequence data of purified HRF-MNC components to determine whether HRF is related to either cytokine. Regardless, this study describes a new function for IL 3 and GM-CSF and represents the first identified HRFs that are potent and effective in most subjects tested.

\section{References}

1. Schulman, E. S., M. C. Liu, D. Proud, D. W. MacGlashan, Jr., L. M. Lichtenstein, and M. Plaut. 1985. Human lung macrophages induce histamine release from basophils and mast cells. Am. Rev. Respir. Dis. 131:230-235.

2. Liu, M. C., D. Proud, L. M. Lichtenstein, D. W. MacGlashan, Jr., R. P. Schleimer, N. F. Adkinson, A. Kagey-Sobotka, E. S. Schulman, and M. Plaut. 1986. Human lung macrophage-derived histamine releasing activity is due to IgE-dependent factors. J. Immunol. 136:2588-2595.

3. Sedgwick, B. D., P. G. Holt, and B. Turner. 1981. Production of a histamine releasing lymphokine by antigen or mitogen-stimulated human peripheral T cells. Clin. Exp. Immunol. 45:409-418.

4. Goetzl, E. J., D. W. Foster, and D. G. Payan. 1984. A basophil activating factor from human $T$ lymphocytes. Immunology. 53:227234.

5. Orchard, M. A., A. Kagey-Sobotka, D. Proud, and L. M. Lichtenstein. 1986. Basophil histamine release induced by a substance from stimulated platelets. J. Immunol. 136:2240-2244.

6. White, M. V., and M. A. Kaliner. 1987. Neutrophils and mast cells. I. Human neutrophil derived histamine releasing activity (HRAN). J. Immunol. 139:1624-1630.

7. Thueson, D. O., L. S. Speck, M. A. Lett-Brown, and J. A. Grant. 1979. Histamine releasing activity (HRA). I. Production by mitogen or antigen-stimulated buman mononuclear cells. J. Immunol. 123:625632.

8. Kaplan, A. P., M. Haak-Frendscho, A. Fauci, C. Dinarello, and E. Halbert. 1985. A histamine releasing factor from activated human mononuclear cells. J. Immunol. 135:2027-2032.

9. Ezeumuzie, I. G., and E. S. K. Assem. 1983. A study of histamine release from human basophils and lung mast cells by products of lymphocyte stimulation. Agents Actions. 13:222-230.

10. MacDonald, S. M., L. M. Lichtenstein, D. Proud, M. Plaut, R. M. Naclerio, D. W. MacGlashan, Jr., and A. Kagey-Sobotka. 1987. Studies of IgE-dependent histamine releasing factors: heterogeneity of IgE. J. Immunol. 139:506-512.

11. Haak-Frendscho, M., S. Satnick, M. L. Baeza, C. Dinarello, and A. P. Kaplan. 1986. Recombinant interleukin 1 causes histamine release from human basophils. J. Allergy Clin. Immunol. 78:237. (Abstr.)

12. Subramanian, N., and M. A. Bray. 1987. Interleukin I causes histamine release from human basophils and mast cells in vitro. $J$. Immunol. 138:271-275.

13. Haak-Frendscho, M., C. Dinarello, and A. P. Kaplan. 1988. Recombinant human interleukin I beta causes histamine release from human basophils. J. Allergy Clin. Immunol. In press.

14. Lee, F., T. Yokota, T. Otsuka, L. Gemmel, N. Larson, J. Luh, K. Arai, and D. Rennick. 1985. Isolation of cDNA for a human granulocyte-macrophage colony stimulating factor by functional expression in mammalian cells. Proc. Natl. Acad. Sci. USA. 82:4360-4364.
15. Yokota, T., T. Otsuka, T. Mossmann, J. Banchereau, T. DeFrance, D. Blanchard, J. E. DeVries, F. Lee, and K. Arai. 1986. Isolation and characterization of a human interleukin cDNA clone, homologous to mouse B-cell stimulatory factor 1, that expresses B-cell- and T-cell-stimulating activities. Proc. Natl. Acad. Sci. USA. 83:58945898.

16. Yokota, T., R. L. Coffmann, H. Hagiwara, D. M. Rennick, Y. Takebe, K. Yokota, L. Gemmell, B. Shrader, G. Yang, P. Meyerson, J. Luh, P. Hoy, J. Pene, F. Briere, J. Banchereau, J. DeVries, F. D. Lee, N. Arai, and K. Arai. 1987. Isolation and characterization of lymphokine cDNA clones encoding mouse and human IgA-enhancing factor and eosinophil colony stimulating factor activities: relationship to interleukin 5. Proc. Natl. Acad. Sci. USA. 84:7388-7392.

17. Yokota, T., F. Lee, D. Rennick, C. Hall, N. Arai, T. Mossman, G. Nabel, H. Cantor, and K. Arai. 1984. Isolation and characterization of a mouse cDNA clone that expresses mast-cell growth-factor activity in monkey cells. Proc. Natl. Acad. Sci. USA. 81:1070-1074.

18. Beaven, M. A., A. Jacobsen, and Z. Horakova. 1972. Modification of an enzymatic isotopic assay of histamine and its application to measurement of histamine in tissue, serum and urine. Clin. Chim. Acta. 37:91-103.

19. Metcalf, D., C. G. Begley, G. R. Johnson, N. A. Nicola, A. F. Lopez, and D. J. Williamson. 1986. Effects of purified bacterially synthesized murine multi-CSF (IL-3) on hematopoiesis in normal adult mice. Blood. 68:46-57.

20. Lopez, A. F., D. J. Williamson, J. R. Gamble, C. G. Begley, J. M. Harlan, S. J. Klebnoff, A. Waltersdorph, G. Wong, S. C. Clark, and M. A. Vadas. 1986. Recombinant human granulocyte-macrophage colony-stimulating factor stimulates in vitro mature human neutrophil and eosinophil function, surface receptor expression, and survival. J. Clin. Invest. 78:1220-1228.

21. Razin, E., J. N. Ihle, D. Seldin, J. M. Mencia-Huerta, H. R. Katz, P. A. LeBlanc, A. Hein, J. P. Caulfield, K. F. Austen, and R. L. Stevens. 1984. Interleukin 3: a differentiation and growth factor for the mouse mast cell that contains chondroitin sulfate $E$ proteoglycan. $J$. Immunol. 132:1479-1486.

22. Irani, A. A., R. Buckly, B. Haynes, N. M. Schecter, and L. B. Schwartz. 1987. Selective depletion of tryptase mast cells in intestinal mucosa of patients with defective T-lymphocyte functions. J. Allergy Clin. Immunol. 79:179. (Abstr.)

23. Irani, A. M., N. Golzar, G. Deblois, and B. L. Gruber. 1987. Distribution of mast cell subsets in rheumatoid arthritis and osteoarthritis synovia. Arthritis Rheum. 30:570. (Abstr.)

24. Gruber, B., M. Poznansky, E. Boss, J. Partin, P. Gorevic, and A. P. Kaplan. 1986. Characterization and functional studies of rheumatoid synovial mast cells: activation by secretagogues, anti-IgE, and a histamine-releasing lymphokine. Arthritis Rheum. 29:944-955.

25. Snapper, C. M., and W. E. Paul. 1987. Interferon- $\gamma$ and B cell stimulatory factor-1 reciprocally regulate Ig isotype production. Science (Wash. DC). 236:944-947.

26. Hamaguchi, Y., Y. Kanakura, J. Fujita, S.-I. Takeda, T. Nakano, S. Tarui, T. Honjo, and Y. Kitamura. 1987. Interleukin 4 as an essential factor for in vitro clonal growth of murine connective tissuetype mast cells. J. Exp. Med. 165:268-273.

27. Natbony, S. F., M. Phillips, J. M. Elias, H. P. Godfrey, and A. P. Kaplan. 1983. Histologic studies of chronic urticaria. J. Allergy Clin. Immunol. 71:177-183.

28. Elias, J., E. Boss, and A. P. Kaplan. 1986. Studies of the cellular infiltrate of chronic idiopathic urticaria: prominence of T-lymphocytes, monocytes and mast cells. J. Allergy Clin. Immunol. 78:914918.

29. Kaplan, A. P., Z. Horakova, and S. I. Katz. 1978. Assessment of tissue fluid histamine levels in patients with urticaria. J. Allergy Clin. Immunol. 61:350-354.

30. Phanuphak, P., A. L. Schocket, C. M. Arrayave, and P. F. Kohler. 1980. Skin histamine in chronic urticaria. J. Allergy Clin. Immunol. 65:371-375. 